\title{
ETNOGRAFÍA DE LOS VALORES
}

\section{Ethnography of values}

\author{
Ricardo SANMARTÍN ARCE \\ Universidad Complutense de Madrid. Campus de Somosaguas. Facultad \\ de Ciencias Politicas y Sociología. Departamento de Antropología Social. \\ 28223 Madrid. Correo-e: risanmar@jazzfree.com
}

Fecha de aceptación definitiva: marzo de 2001

BIBLID [(1130-3743) 12, 2000, 129-141]

\section{RESUMEN}

Si se desea cambiar los valores a través de la educación, primero es necesario conocer cuáles son los valores reales de la gente. Los valores culturales deben estudiarse empíricamente, fundándose en las técnicas tradicionales que caracterizan el trabajo de campo antropológico: la observación participante y la entrevista. Ése es el mejor modo de apresar los valores culturales realmente sostenidos por la gente. Los valores son modelos culturales de principios morales lentamente construidos en la interacción social y la historia. Cuanto más implícitos o inconscientes son, más eficazmente condicionan el significado y sentido de la conducta social. Los trabajadores de campo intentan captar los valores culturales en acción, mientras están siendo sostenidos por los actores en la interacción social. El artículo explica cómo hacerlo y señala qué áreas y situaciones son más adecuadas para este tipo de investigación social que intenta inferir modelos culturales específicos a partir de la observación empírica.

Descriptores: valores, educación, trabajo de campo, modelos culturales, inconsciente. 
In order to change values through education, first is necessary to know which are the values actually held by people. Cultural values must be studied empirically, relying on the traditional research technics that characterize the anthropological fieldwork: participant observation and interview. This is the best way to apprehend those cultural values truly held by people. Values are cultural models of moral principles slowly built in social interaction and history. As more implicit or unconcious they are, more efficaciously condition the meaning and sense of social behaviour. Fieldworkers try to capture cultural values in action, while they are being held by the actors in social interaction. The article explains how to do so and shows which areas and situations are more suitables for this kind of social research that tries to infer specific cultural models from empirical observation.

Key words: values, education, fildwork, cultural models, unconscious.

Lo que normalmente se entiende por valores son modelos culturales de ciertos grandes principios morales de conducta, apreciados por quienes los comparten. Modelos lentamente generados en la experiencia de la interacción a lo largo de la historia y que se transmiten al ejemplificarlos los actores en su vida social, encarnándolos en la conducta, dando testimonio de ellos. Por ello, como veremos, no nos limitaremos a observar solamente aquellos casos en los que los actores explicitan juicios morales, juicios que parten ante el contraste entre la conducta observada y la implícita imagen de aquellos principios asimilada en su memoria e imaginario cultural. La plasmación de un juicio de valor, aun cuando es una magnífica ocasión para cazar al vuelo un valor en el momento en el que lo están ejercitando los actores, no es el único tipo de manifestación de los valores. Los valores están valiendo en muchas más ocasiones y a todas ellas podemos atender para, desde la observación, inferir la figura del valor.

Los valores son creencias morales fundadas en la experiencia. Contienen bajo su nombre (libertad, igualdad, justicia, solidaridad, orden, respeto, tolerancia...) modos muy concretos de apreciar la bondad de ciertos actos humanos realizados refiriéndose al resto de ciudadanos y sobre cuestiones vitales que a todos afectan. Se fundan en la experiencia porque es en la acumulación de ella en donde nacen esas maneras de juzgar las cosas. Es en esa experiencia como se llega a la convicción de que ésas son las formas correctas de hacer las cosas, de que esa manera de hacerlas es buena, es práctica, resulta funcionalmente bien adaptada para todos o, al menos, para aquellos propósitos que coordinan el conjunto de la co-actividad social, elevando por ello lo meramente práctico a la categoría de bien, un bien sostenido en una especie de implícito consenso democrático, de esa democracia anónima escrita en la historia colectiva. Por eso decimos que se trata de creencias morales. Tienen carácter ideal, pero existen en la realidad cultural de los hombres. No por ser ideales carecen de existencia los valores. No habría nada más irreal que 
considerarlos irreales. A nadie le da igual todo. Las conductas, los actos son más o menos buenos o malos, preferibles o rechazables, deseables o indeseables. No hay actos humanos totalmente irrelevantes por su indiferencia, pues la indiferencia misma es ya una manera de valorarlos.

Quisiera con estas ideas resaltar que la acción humana es siempre una acción moral. La inevitable implicación de cualquier acción, sea ésta educativa, profesional o laboral, con el entramado de acciones sociales propias y ajenas, así como con el marco cultural que al actuar pone en operación, nos hace reconocer que no hay acción social neutra; que en su mismo sentido y significado va inserto un denso juego de valoraciones. Inscrita cualquier acción en su contexto, con su intención o accidentalidad, es ineludible reconocer en ella, formando parte de lo que ella es. Su sentido moral, la presencia de imágenes de valores que contribuyen a su creación.

Es esa misma contemplación moral de la conducta lo que les permite a los actores — sean éstos los profesionales de la educación, sus usuarios o sus familias- distinguir en toda acción sus cualidades básicas, definirla y nombrarla, reconocer y diferenciar una conducta de otra, ya que de modo contextual, según cuándo, cómo, dónde, con quiénes se interactúe y con qué fines, una conducta u otra permitirá al actor un mayor o menor grado de libertad, mayor seguridad o riesgo, un determinado reconocimiento de su identidad personal, una equiparación o una diferenciación con los demás, un distinto grado de solidaridad o de soledad con sus consiguientes contrapesos de dependencia e independencia. En el uso de su cultura, atender, discriminar, evaluar y reconocer se dan conjuntamente para los actores en un mismo acto. Ya nos señalaba Ortega que:

"No somos... en última instancia, conocimiento, puesto que éste depende de un sistema de preferencias que más profundo y anterior existe en nosotros" (Ortega y Gasset, 1993: 143).

Si los valores se fundan en la experiencia compartida, es en esas situaciones vitales en las que los actores se ven llevados inevitablemente a compartirlas y a permanecer en ellas donde efectivamente bulle la génesis cultural de los valores. Se trata pues de situaciones en las que se hace inevitable un compromiso moral entre los actores y, normalmente, tras ello late una fuerza tan inexcusable como la de una necesidad y que llega a percibirse bajo distintas formas de exigencia y expectativas recíprocas. No se trata tan sólo de situaciones vitales propicias para experiencias en las que unos, por necesitar de los otros, fragüen figuras específicas del valor de la solidaridad. En tales situaciones no es ése el único valor que se gesta. También nace ahí la igualdad, el respeto, la tolerancia y muchas otras valoraciones sobre la persona en tensión con la libertad y la identidad. La persistencia de situaciones críticas, la duración de situaciones de cambio o simplemente situaciones de interacción continuada en ámbitos tan dispares como la familia, el trabajo, en el aula, en las reuniones, en la vida pública, a través de la sociabilidad informal, etc., todas ellas son focos en los que se gestan valores adaptados a la peculiaridad de su contexto. 


\section{CREENCIAS MORALES}

Lo que en relación con los valores observamos en el trabajo de campo son las distintas maneras que tienen los actores de expresar sus preferencias. Algunas de ellas son manifestadas verbalmente de un modo relativamente claro mediante juicios de valor, pero la mayoría de las preferencias quedan sobreentendidas en la emisión de críticas positivas y negativas sobre la conducta de aquellos con quienes interactúan; implícitas en comentarios vertidos al hilo de una descripción en una charla, o simplemente resultan inferibles al observar una serie constante de decisiones de elección bajo las que cabe suponer que subyacen igualmente preferencias. Todo ese variado tipo de posibles manifestaciones de los actores, que sin duda se apoyan en valores, puede llegar a cristalizar y encarnarse en instituciones, en principios morales que se inculcan en los procesos de socialización, en normas expresas organizadas incluso en leyes y reglamentos. Pero el valor que hace posible la preferencia queda siempre implícito incluso para el propio actor. Lo que llegamos pues a aprehender es la valoración que subyace a todas esas conductas observables. El valor como tal es un modelo moral cuya existencia predicamos tras inferirla al interpretar las valoraciones que hemos aprehendido en el trabajo de campo, pero no obtenemos — ni buscamos- de los informantes su explícita descripción. No quisiera con esto afirmar una completa oscuridad del valor incluso para sus portadores. Sin duda es más realista describir el caso reconociendo la existencia de una gradación entre consciencia y subconsciencia de los valores. Tampoco significa esto que los actores sean incapaces de percibir en qué principios fundan sus preferencias o en base a qué evaluación toman sus decisiones. En todo ello hay que reconocer grados. Con todo, los grados paradójicamente más fiables para construir la etnografía son, como ya sabía F. Boas, los menos conscientes, los que así resultan menos manipulables por racionalizaciones interesadas del actor frente al investigador. Más aún, tendríamos que reconocer que, en realidad, los valores que valen de un modo eficaz son aquellos que, aunque parezca contradictorio, se le imponen al actor en su interior aun en contra de sus intereses.

Aun cuando a lo que apunta esta última paradoja es a la existencia de una jerarquía de valores, ese peso coactivo tan imperioso de los valores que ocupan la cúspide de la misma — capaces por tanto de enfrentarse a los que, más abajo, sólo alcanzan el estatuto de "intereses" — nos ayuda a comprender la naturaleza creencial de los valores. Del mismo modo que sucede con las creencias en las que, como decía Ortega, se está en ellas aun sin saberlo, sucede con los valores, en los que, como creencias morales, en ellos estamos aun sin saberlo.

En tanto que instrumentos que nos ayudan a discriminar lo preferente, los valores nos discriminan el mundo. Desde ellos damos forma a cada cosa que es contemplada, seleccionada y reconocida. Ese proceso categorizador de la realidad, que juega con los límites de las cosas y las conductas, que los hace y rehace situacionalmente logrando, no obstante, una singular coherencia, un cierto estilo reconocible es, pues, tan cognitivo como moral. A la vez que fundado en sus valores 
el actor va tentando el panorama histórico en derredor, las situaciones, las circunstancias y su problematicidad, va invistiendo de significado lo que contempla. Valorar es dotar de sentido lo valorado y así es también nombrar, distinguir, categorizar y clasificar, introducir un orden, una jerarquía, un reconocimiento y un sentido. Así está hecha la cultura. Como nos sigue recordando Max Weber:

"El concepto de cultura es un concepto de valor. La realidad empírica es para nosotros "cultura" en cuanto la relacionamos con ideas de valor; abarca aquellos elementos de la realidad que mediante esa relación se vuelven significativos para nosotros, y sólo esos" (Weber, 1997: 65).

\section{Podemos con Weber reconocer que:}

"Únicamente una pequeña parte de la realidad individual considerada en cada caso está coloreada por nuestro interés condicionado por aquellas ideas de valor; ella sola tiene significación para nosotros, y la tiene porque exhibe relaciones para nosotros importantes a causa de su ligazón con ideas de valor" (Weber, 1997: 65-66).

Así pues, si los valores son importantes es, ante todo, porque se imponen a los actores. Los actores ven por ellos regida su conducta, como decía, incluso en contra de sus propios intereses. De ahí que sea más fiel a la naturaleza de los valores estudiarlos en vivo, detectarlos cuando están valiendo, aunque no se den cuenta de ello los propios actores que, de hecho, los están aplicando en su conducta. Más pues que preguntar por ellos, intentaremos captarlos mientras están valiendo. No tiene mucho sentido preguntar a los actores cuáles son sus valores, ya que los valores de verdad, los que valen de hecho, los que se imponen a los propios actores, son inconscientes. Hay que inferirlos de la observación de la conducta o de las opiniones vertidas en la conversación.

Si los valores orientan la conducta y los valores valiosos — valga la redundanciason inconscientes, no quiere esto decir que los actores orienten a ciegas su conducta. El grado en el que los valores se hacen explícitos a la conciencia de su portador es, obviamente, variable. Lo que quisiera subrayar es que a mayor inconsciencia del valor, mayor potencia o fuerza posee para marcar la conducta. Éstos, por tanto, serán los que en mayor medida nos interesen como antropólogos sociales.

\section{ETNOGRAFIAR LOS VALORES}

Pero ¿hacia dónde dirigiremos nuestra mirada y nuestra escucha para encontrar esas creencias morales? Entendidos los valores como creencias morales, buscamos apresar su figura en el trabajo de campo cuando están operando, cuando los actores los usan en sus valoraciones, cuando están valiendo. Son esos momentos en los cuales los actores encarnan los valores en su conducta. Es entonces cuando con mayor fiabilidad podemos orientar hacia ellos nuestra observación con la intención de inferirlos desde su estado de creencia activada, operante. 
Por eso, dada su naturaleza, más que preguntar por ellos los observamos o, mejor dicho, los inferimos observándolos de la conducta que los encarna. Sólo podremos aprehenderlos en el sostén conductual de los actores, en su testimonio. Tal como pasan los valores de un actor a otro, así como en ellos son enculturados los actores socializándose, del mismo modo tendremos que aprehenderlos en el trabajo de campo. Nunca será equivalente que un informante nos nombre el valor de la libertad o el de la igualdad, que nos ordene la jerarquía de sus preferencias o las relaciones entre ellos, y así lleguemos a conocer dichos valores, que desentrañar el contenido real de esos valores a través del testimonio que de los mismos nos dan los actores en nuestra interacción con ellos. Esa forma de aprehenderlo contiene un más hondo y extenso conocimiento del valor por haberse obtenido por experiencia, esto es, conectando la vivencia de la interacción con el actor, la observación, la situación de encuentro humano que el trabajo de campo implica, con el fondo personal del propio investigador, iniciándose ahí un primer momento de comparación cultural. No por mucho pedir orden lo encarna un maestro que pida a gritos a sus alumnos que guarden silencio. Cuando observamos en el aula al maestro gritar: “No chilléis!», en su misma conducta está encarnando lo contrario de lo que afirma. Es lo encarnado en la conducta lo que se transmite, aquello por lo que ésta se rige de hecho. Los valores aun con ser modelos ideales, sólo existen de hecho, no de dicto.

Si en las crisis y cambios se favorece la fluctuación de los valores, ése podría ser un caso etnográfico favorable para el estudio de la cultura desde la óptica de los valores. La desorientación sufrida por los actores en los procesos de cambio lleva a un sobreesfuerzo imaginativo tratando de adaptar las viejas figuras de los valores a las nuevas situaciones. La creatividad cultural bulle y ése es siempre un buen contexto para el trabajo antropológico. La tensión frente a la realidad, propia del carácter ideal de los valores, ve también intensificada su función en tales situaciones a través de la crítica ante cualquier propuesta o alternativa y, de ese modo, resultan más visibles los valores.

Con todo, no cabe deducir que las situaciones más estables y cotidianas sean menos favorables para el estudio que proponemos. Será otra la dirección de la mirada. La vida cotidiana está llena de situaciones tensas, críticas, plagada de pequeños conflictos. Vivir constituye siempre de algún modo una cierta supervivencia. Si nuestra cultura es tan tensa y aspiracional como parece, el peso de los componentes ideales se dejará notar con relativa facilidad casi en cualquier situación. Eso no significa que el observador no necesite aguzar su oído y su mirada, su misma sensibilidad moral, para atender a la irrupción de cualquier matiz relevante en la vida cotidiana. No sólo pues el cambio, la crisis, el conflicto, sino también los focos permanentes de preocupación sobre los que se centra la atención colectiva en cada cultura constituyen un campo privilegiado para el estudio de los valores. En buena medida, lo que hemos distinguido como valores son maneras concretas de encarnar esa preocupación cultural por ciertos ámbitos de conducta que así se ven valorativamente diferenciados y especificados. Allí pues donde una cultura concentre 
su atención irrumpirán más y más matizadas valoraciones que darán pie a nuevas y específicas categorizaciones. Las áreas en las que tal atención cultural predomina no son solamente las relativas a preocupaciones coyunturales. En nuestro país, por ejemplo, con la modernización de la economía y la profesionalización del trabajo se ha dado un proceso de aprendizaje que ha exigido renovar las valoraciones y discriminar muchos tipos de conducta. Algo similar ha ocurrido en la vida pública, con el impacto de la inmigración y la siempre difícil acogida de quienes poseen una cultura diferente. Incluso la observación en las escuelas e institutos de esos momentos de acogida, de los contactos para informar a quienes, siendo o no extranjeros, acuden por vez primera al centro, constituyen puntos para la observación de los valores que, de hecho, rigen la conducta de los profesionales de la educación, tanto o más que la de los inmigrantes. Todo ello son campos especialmente aptos para el ejercicio de la observación de la irrupción de valoraciones por parte de los actores, para el estudio de las decisiones que implican elección entre alternativas expresivas de preferencias. También lo es el mundo del consumo. La orientación simbolista en el estudio del consumo que ejemplificó en los años setenta Mary Douglas (Douglas e Isherwood, 1978) puede seguir siendo foco de nuestra atención para aprehender en acción las valoraciones de los actores, sus aspiraciones y la expresión jerarquizada de sus deseos, tras todo lo cual subyacen principios orientadores de su acción. Es ése un campo excelente para la detección de las pautas enseñadas y aprendidas a través del consumo alimentario. Ahí, en las escuelas, no es difícil observar cómo se transmiten valores en la mesa, cómo se ejemplifica y se encarna el orden, la sobriedad o la facilidad sensual del individuo, el aprendizaje de límites y de normas como vehículo que canalice la solidaridad con los compañeros de mesa, de aula, etc.

Muchas de esas preferencias relativas al trabajo, a la economía, al derecho, a la propiedad, a la salud, a la familia o a la política acaban plasmándose en normas organizadas, en reglamentaciones, en la planificación misma del curso escolar cuyo texto podemos estudiar junto con su aplicación práctica, con la observación de su transgresión o su cumplimiento eficaz, siendo ambos extremos relevantes para una correcta comprensión de los valores, ya que la vigencia de un valor no podemos apreciarla tan sólo en base a tales textos, ni tan sólo en función de las conductas que lo cumplen. Los juicios de valor que sancionan críticamente las conductas negativas son emitidos por los actores desde una posición vital que sitúa al actor en el valor al que se adhiere. Desde ahí es capaz de emitir su juicio criticando las conductas que vulneran el valor. Nos recuerdan esos casos, una vez más, que el valor y el contravalor no son sino extremos de un rango de preocupación cultural que enfoca la atención de una determinada cultura. Por eso ambos son relevantes para especificar el área de dicha preocupación que tipifica el estilo de la cultura.

Además de atender a los cambios, a las crisis, a las zonas de preocupación cultural; además de estudiar las normas y reglamentos, de escuchar los juicios de valor, las preferencias, deseos, elecciones y decisiones, dirigiremos también nuestra atención hacia esas otras áreas de conducta en las que parece no ocurrir nada, a la 
rutina cotidiana, a aquellas en las cuales los actores se entienden recíprocamente sin mayores problemas, adivinándose unos a otros, ya que tal intelección sólo es posible si se comparten hondamente unos mismos valores. Aquellas áreas de conducta en las que los actores no necesiten explicitar su recíproca intelección, en las que su comprensión mutua quede implícita, las discriminaciones y preferencias operan como verdaderas creencias compartidas, con la solidez de lo real. Estaremos, pues, ante valores compartidos en su más estable estado creencial; difíciles de estudiar, pero ése es el reto.

En cualquier caso, por llevar aparejados los valores una emoción como efecto de la percepción de sus contenidos ideales, podremos buscar valores allí donde florezcan dichas emociones: en la vida familiar o en la amistad, en las tensiones y éxitos profesionales, etc. No sólo emoción, sino ésta como efecto de contenidos ideales fraguados en la experiencia histórica, es lo que integra el valor. Una y otros se transmiten unidos en los procesos de socialización y, por ello, ésos serán nuevos escenarios hacia los que dirigiremos nuestra observación para captar la presencia de los valores culturales en acción, transmitiéndose de unas a otras generaciones, de unos a otros actores al ejemplificarlos y encarnarlos en conducta, al educarnos unos a otros. Padres e hijos, maestros y alumnos, amigos y amigos, compañeros y competidores nos damos unos a otros testimonio de un patrimonio ideal y emotivo en el que se condensa una sabiduría moral decantada por la historia.

La aplicación de los valores no se realiza sólo en decisiones y elecciones explícitas. Si, como decía, en las normas hay, implícitos en ellas, valores, eso mismo nos permite tomar las normas, incluso las instituciones mismas a las que tales normas pertenecen, como encarnaciones o cristalizaciones de valores. Toda norma, escrita o no, detectada en la manera repetida y sancionada de hacer las cosas, define una manera buena o correcta de hacer algo y una manera incorrecta o mala de hacer las cosas. En esa sanción de la conducta ya se nos está ofreciendo una valoración de la conducta. Si se nos dice que la vigilancia del comedor escolar ha de hacerse por turnos equivalentes y por parte de todos los educadores, se está sancionando tanto el valor de la solidaridad, como el de la igualdad. Si algún compañero no cumple con su parte y es criticado por ello, se le hace el vacío o se le aplica cualquier otra sanción, no quiere decir que no estén vigentes en ese caso la solidaridad o la igualdad. Precisamente es desde su vigencia como cabe reconocer la negatividad de dicha conducta. Es más, según se aprecie en la manera concreta de contarlo los informantes se podrán ver matices expresivos de las razones que asisten tanto al maestro renuente como a la autoridad que exige la colaboración y aplica la sanción. Según acepten excusas, motivos, intenciones, etc., podremos apreciar matices desde los cuales inferir valoraciones sobre la persona, su responsabilidad, su salud o sus circunstancias como eximentes, etc. Ahí podremos apreciar tensiones muy específicas entre la vida familiar y la laboral, la privada y la pública, etc.

En otros casos podemos observar ciertos tipos de instituciones grupales o asociaciones en las que la propia institución plantea una serie de requisitos para aceptar 
a alguien como miembro. Conocer bien todas las normas que rigen la entrada y la permanencia en una institución es fundamental para empezar a conocer la cultura de los actores. En tales normas o requisitos se plasman exigencias que traducen principios prácticos que, dada su experiencia y su ya comprobada efectividad, han terminando elevando lo funcional a la categoría de moralidad. En ese sentido, las normas institucionales encarnan valores en donde lo útil se transforma en bien moral. Es posible que tales normas de ingreso o reclutamiento exijan cierta edad, condición o cualificación, aportar ciertos bienes, dinero o instrumentos, etc., todo lo cual nos hablará de principios o valores que a todo ello subyace. En última instancia se está prefiriendo que para tal institución los integrantes sean hombres o mujeres, profesionales de un tipo o de otro, que sepan o puedan hacer tal cosa o tal otra y así sucesivamente, lo cual nos indica sus preferencias, esto es, sus valoraciones, las cuales se fundan en ciertas específicas imágenes de valor que de ese modo iremos infiriendo.

No sólo en normas e instituciones. Los actores actúan estratégicamente. Son seres racionales que toman incluso las normas como recursos normativos a usar para sus fines e intereses. Estos mismos, los intereses, implican valoraciones. ¿Por qué a los actores les interesa esto o aquello? Si les interesa será porque de algún modo lo valoran. Es más, las estrategias concretas que elaboran para alcanzar esos fines o intereses también nos vuelven a hablar de las preferencias de los actores, de la negociación o compromiso entre eficacia (en relación a sus fines) y principios morales. Actuar estratégicamente implica preferir una u otra línea de actuación. Tendremos que comparar esas estrategias con el panorama más general de las situaciones en las que se aplican y del contexto global del lugar en el que estemos estudiando para encontrar las claves de la razonabilidad de tales preferencias. De ese modo podremos empezar a comprender qué valores han guiado esas decisiones. Si los actores están dispuestos a pagar un cierto precio, en términos de esfuerzo o coste humano, para el logro de un determinado objetivo, ahí tendremos una medida aproximada del valor relativo de ambos extremos: del objetivo y del coste humano, todo lo cual nos irá ayudando a matizar de un modo muy ajustado a su cultura, a su lugar y época, lo que encierra el valor bajo la aparente uniformidad de su nombre. ¿Qué estrategias adoptan a la hora de asumir un cargo o una función en el seno de la institución docente? ¿Qué estrategias se siguen en el seno de las reuniones profesionales? ¿Cómo se desarrollan las reuniones entre padres y maestros a lo largo de todo el curso escolar? ¿Hay o no competitividad implícita entre ambas partes? ¿Cómo son los encuentros y relaciones entre los centros y la Administración? ¿Cuáles son las costumbres instituidas, enraizadas en la práctica diaria de funcionamiento de cada centro? En relación con los inmigrantes ¿cómo se relacionan los docentes con el pluralismo cultural? ¿Se percibe como algo que no va a ser meramente pasajero o temporal, sino como algo permanente? ¿Cuánto se parece la conducta diaria en los centros y los contenidos de la planificación? ¿Se les plantean a los alumnos con claridad, no sólo verbalmente, las normas generales? De todo ese conjunto de observaciones puede surgir un montón de etnografía que luego 
habrá que estudiar lentamente, comparándola con las transcripciones de las entrevistas que se realicen a todas las partes implicadas en el proceso educativo: profesores, alumnos, familias, Administración...

Además de las instituciones, normas y estrategias, otro foco de nuestra atención serán los rituales (saludos, recepción de nuevos miembros, reuniones, fiestas, entrega de premios...). En cualquier ritual tanto en sus fases y procesos, como en los elementos que en él se integran, encontraremos una abundante actividad simbólica en la que aparecerán valores simbolizados ritualmente. Según qué elementos elijan los actores para formar su ritual, el modo como los combinen y la forma que otorguen al mismo, se estará simbolizando ciertos principios que son valorados y en los que creen como regidores de su vida colectiva. Incluso en los aspectos meramente técnicos o prácticos de la construcción del ritual podemos ver plasmados valores. Si, por ejemplo, observamos una fiesta de fin de curso, podemos fijarnos en cómo se distribuyen los actores en posiciones sancionadas como propias del ritual, ¿quiénes presiden la reunión y cómo?, ¿cómo se visten?, ¿qué hacen?, ¿qué posiciones ocupan?, ¿qué fases o partes componen la celebración?, y ¿cómo razonan y explican todo ello los actores? De esas y otras preguntas podemos ir infiriendo valoraciones implícitas a las decisiones que llevan a sostener tal ritual, con esos elementos, forma y proceso.

Decía antes que no tiene mucho sentido preguntar directamente por los valores, pero eso no significa que no contemos con las opiniones de los actores. Atender a sus palabras, a sus opiniones y juicios es fundamental en todo trabajo de campo. Sin duda una de las formas más claras de apresar los valores en el momento en el que están valiendo es atender a la formulación de juicios de valor por parte de los informantes. No me refiero tanto a nuestra solicitud de que juzguen hechos o conductas ajenas, sino a la atenta escucha de los juicios espontáneamente emitidos por los actores al hilo de la conversación. Obviamente, las entrevistas versarán sobre temas descriptivos del proceso escolar, no directamente sobre valores. Pero si tenemos sus palabras registradas en nuestro magnetófono podremos después estudiar el amplio contenido valorativo que siempre encierran, tanto a través de sus juicios de valor explícitos como, de modo más implícito, a través de sus opiniones. Fijándonos en las comparaciones que establecen entre hechos ocurridos o acciones que nosotros mismos podemos haber contemplado en el centro, es fácil detectar la jerarquía que establecen, la preferencia por una o por otras y las razones de tales preferencias. Asimismo, en sus comentarios podremos percibir cómo, al asociar una idea con otra o al contrastar y oponer unas con otras, se deslizan valoraciones aun sin que ellos mismos se den cuenta. En otros casos no sólo nos comentarán sus elecciones, las decisiones que han tomado en la vida y que, por tanto, presuponen el uso de figuras de valor para tomarlas, sino que podremos observar esas elecciones y decisiones en la vida cotidiana en un muy amplio campo de situaciones, asuntos y problemas.

Finalmente, esbozadas las figuras de los valores a partir de la observación, la entrevista y la inferencia que de todo ello alcancemos, iremos percibiendo el modo 
como unos valores se implican con otros. Lo que observamos es cómo los actores significan su realidad desde un estratégico juego de relaciones de valor. No irrumpen en solitario, sino entrelazadamente unos y otros valores, y el modo de entrelazarse, de depender algún aspecto o perfil de la figura de un valor de las peculiaridades de los otros nos ayudará a tener una más unificada figura del conjunto de la sabiduría moral de la cultura que estudiamos.

Para, a partir de todas esas observaciones, llegar a inferir los valores en ellas encarnados, tendremos que penetrar en esa etnografía, desde nuestra personal apreciación de su relevancia, esto es, captando su mérito o importancia como problema digno de ser desentrañado para una mejora educativa. Claro está que para desentrañar un problema hay que entrañarlo primero. Los hechos humanos no se nos revelan, no se dejan entender, sin un sujeto humano que primero los entrañe para poder luego desentrañarlos. Aquí se nos revela un primer paso necesario que tipifica la estrategia del investigador de campo. Es en la convivencia con los actores, en el trabajo de campo intensivo y prolongado, como entramos en contacto con quienes sostienen en su conducta los valores. En ese encuentro con todo un sistema diferente de concebir la moralidad de la vida en tantos campos de experiencia (familiar, educativo, económico, político, religioso, estético), con tan sutiles matices que difieren de los nuestros incluso en aquellos casos en que más se asemejan, surge la incomodidad del reto que la alteridad nos plantea a los hombres. El investigador, incómodo ante la disparidad de valores a la que se enfrenta, buscará un nuevo horizonte de moralidad en el que quepan ambas como versiones humanamente posibles. Para ello tendrá que ser capaz de recorrer empáticamente la distancia existente entre los valores propios y los ajenos; de mover su mente y situarse en ambas posiciones hasta entender las dos como versiones de ese nuevo horizonte el cual, una vez alcanzado, podrá proponerlo como su comprensión o interpretación posible.

No llegamos así, de golpe y a la primera observación, a formarnos una imagen, ni definitiva, ni suficiente de los valores. Todo lo humano es un material tan delicado que no es fácil de estudiar. Exige paciencia y dedicación, atención esmerada y ferviente, fina observación y reflexión crítica de lo observado. No se puede estudiar mediante recetas técnicas o de fórmulas ya preparadas, de cuya simple aplicación pudieran surgir resultados aceptables. En estos temas humanos hay que implicarse personalmente, reconocer que nuestra propia persona como investigadores es la primera y principal herramienta de trabajo para alcanzar, a través de nuestra subjetividad, el conocimiento. En realidad, usamos una primera imagen de los valores ajenos como modelo provisional que vamos poco a poco corrigiendo, y lo hacemos a la vez que vamos cambiando el campo de experiencia sobre el que proyectamos nuestra observación. De un primer contraste entre valores propios y ajenos, pasamos a otro entre valores dentro de ese mismo marco cultural pero en ámbitos distintos: la familia y la escuela, la Administración y el centro, por ejemplo. Esto es, de la comparación intercultural, de ese contraste percibido en nuestro interior, pasamos a la comparación intra-cultural. 
Pero reconocer la necesidad del uso de nuestra persona, con toda su sensibilidad receptiva, como herramienta de investigación, no significa introducir la arbitrariedad ni etnocentrismo, sino el empeño del investigador como ya reconoció Max Weber diciendo que:

"Sin las ideas de valor del investigador no existiría ningún principio de selección del material ni conocimiento provisto de sentido de lo real... sin la fe del investigador en la significación de cualquier contenido cultural toda labor de conocimiento de la realidad individual carecería... de sentido... su labor estará orientada por la dirección de su fe personal, por la refracción de los valores en el prisma de su alma" (Weber, 1997: 71).

Precisamente para que la modelación de lo ajeno resulte efectivamente descriptiva de sus creencias morales y quede el menor resto etnocéntrico posible, es por lo que el proceso de dilución de las imágenes propias ante el reto de las ajenas ha de ser hondo y sostenido. Es así como entrañamos el problema. Curiosamente, cuanto más arriesgamos la firmeza de nuestras creencias - sean morales o no- mejor conocemos la naturaleza de cualquier creencia. Vamos por pasos, aproximándonos poco a poco. Si en un primer momento de contraste intercultural usamos nuestras ideas de valor en la relación de valor y como pre-juicio interpretativo, en un segundo momento de comparación intra-cultural usamos la imagen de su valor previamente esbozada en un campo de experiencia (por ejemplo, la familia) como modelo posible para el ensayo interpretativo en otro de sus campos de experiencia (digamos, la escuela), con lo cual, esa primera modelación del valor ajeno opera como pre-juicio interpretativo en esa fase de comparación intra-cultural.

Nuevamente este proceso es tentativo. En primer lugar, al chocar nuestra sensibilidad vital con la cultura ajena, ponemos las ideas desprendidas de nuestros valores en contacto con las ideas de los valores ajenos. En segundo lugar, al sentir el contraste, la semejanza y la diferencia de matices, empezamos a atisbar aquello en lo que cada idea de valor ajena pudiera consistir. El tercer momento, más dilatado, nos permitirá reunirlas al percibir valoraciones nativas equivalentes en situaciones y experiencias diferentes. Esa topología de un mismo valor, esa conservación dinámica de la figura que el conjunto de sus componentes ideales forman, a pesar de las transformaciones que la situación le impone, expresa ya una parte del cemento vital, afectivo, que su vivencia provoca como resultado en los actores. Con todo, necesitamos completar la interpretación de la figura de cada valor atendiendo al modo como se entrama con el resto en esas mismas situaciones vitales en las que hemos ido apreciando su irrupción. A semejanza de lo que proponía Ortega, contemplados por dentro los valores como hechos moralmente cruciales "se les dota de transparencia... y merced a... esto nos sirven como nuevos órganos oculares, como lentes de aumento que esclarecen... el resto" (Ortega, 1994: 150) de la cultura ajena. Si la cultura está hecha de valores y creencias, comprender los valores de una cultura es un buen primer paso para comprenderla y comprender a los actores que la crean. 
RICARDO SANMARTÍN ARCE

\section{BibliograFIA}

Douglas, M. e IsHerwood, B. (1978): The World of Goods. Towards an Anthropology of Consumption. Penguin Books.

ORTEGA y GASSET, J. (1993 [1940]): "Ideas y creencias". Revista de Occidente. Alianza Editorial, Madrid.

- (1994 [1921]): "España invertebrada”. Revista de Occidente. Alianza Editorial, Madrid.

SANMARTIN ARCE, R. (1999): Valores culturales. El cambio social entre la tradición y la modernidad. Ed. Comares, Granada.

WeBER, M. (1997 [1922]): Ensayos sobre metodología sociológica. Amorrortu ed. S.A., Buenos Aires. 